\title{
ENSAIOS
}

\section{A PRODUÇÃO LITERÁRIA SOBRE HOMOFOBIA INTERNALIZADA}

\author{
Daniel Cerdeira de Souza ${ }^{1}$ \\ Andrews do Nascimento Duque ${ }^{2}$ \\ Icaro Gonçalves de Castro ${ }^{3}$ \\ Iramilson da Silva Mesquita ${ }^{4}$
}

Resumo: Este estudo caracteriza-se por ser uma revisão de literatura que aborda a produção sobre Homofobia Internalizada (HI) entre 2010-2017. Objetivamos discutir como a literatura aborda sua manifestação, quais fatores relacionados à mesma e suas consequências. Para isso, selecionamos 22 artigos através dos descritores "Homofobia AND Internalizada" das bases de dados Scielo, Pepsic e CAPES nas línguas portuguesa, inglesa e espanhola. Os artigos colhidos foram analisados através de um protocolo criado pelos autores. Os resultados discutem que homossexuais internalizam o estigma contra a homossexualidade desde tenra idade e isso os prejudica na formação de uma identidade saudável, além do que, estes estão em maior vulnerabilidade para o uso de álcool, outras drogas e suicídio. A HI é projetada na forma de ódio contra homossexuais que não atendem ao binarismo de gênero. E atinge com mais força ainda os homossexuais ditos "afeminados". A religião possui forte papel na internalização de estigmas e é preciso vencer a HI para viver sua orientação sexual de maneira saudável e plena.

Palavras-Chave: Homofobia Internalizada; Heteronormatividade; Consequências; Revisão de Literatura.

\section{Introdução}

Este estudo é de caráter descritivo e objetiva analisar a literatura científica no formato de artigos científicos indexados entre 2010-2017 sobre a Homofobia Internalizada (HI). As pesquisas descritivas descrevem criteriosamente os fatos e

\footnotetext{
${ }^{1}$ Doutorando em Psicologia (UFSC), Mestre em Psicologia (UFAM), especialista em Terapia Cognitivo Comportamental, psicólogo. E-mail: dancerdeira01@gmail.com

${ }^{2}$ Mestre em Psicologia (UFAM), psicólogo. E-mail: andrews.duque@gmail.com

${ }^{3}$ Especialista em Terapia Cognitivo Comportamental, especialista em Avaliação Psicológica, psicólogo. E-mail: icarocastropsi@gmail.com

${ }^{4}$ Psicólogo. E-mail: hiramesquita40@gmail.com
}

Vol. 02, N. 01, Jan. - Mar., 2019 - www.revistas.unilab.edu.br/index.php/rebeh 
fenômenos de determinada realidade, de forma a obter informações a respeito daquilo que já se definiu como problema a ser investigado (TRIVIÑOS, 2008).

De maneira geral, a manifestação explícita do preconceito tem diminuído nas últimas décadas, porém essa redução se verifica apenas em grupos protegidos socialmente. Contra grupos que não estão protegidos, a manifestação ainda persiste com grande intensidade. Exemplo disso é o preconceito contra homossexuais. (PEREIRA et al, 2011, RIOS, 2011). O termo homofobia é utilizado para a conceitualização da violência e discriminação contra indivíduos que apresentem orientação sexual diferente da heterossexual (COSTA, NARDI, 2015).

A homofobia é causada por normas sociais dominantes derivadas do sistema de gênero. Podemos citar o heterossexismo ou heteronorma, que é o sistema ideológico que nega, ridiculariza e estigmatiza qualquer forma de comportamento, identidade, relação ou comunidade diferente da heterossexual. Nessa perspectiva, a partir dos pressupostos históricos e culturais, há a imposição de uma linearidade entre sexo biológico, gênero e orientação sexual, onde os machos devem ser masculinos e as fêmeas devem ser femininas. Culturalmente, a homossexualidade é a transgressão dos estereótipos de gênero: os homens homossexuais são pensados como feminino e lésbicas como masculino, existindo uma oposição entre heterossexualidade e homossexualidade (ORTIZ-HERNÁNDEZ, 2005; COSTA, NARDI, 2015; MELLO, 2012).

Ademais, outra regra dominante é o machismo, que consiste na subordinação ou inferioridade do feminino antes do masculino, isto é, as características, atitudes e valores considerados masculinos são avaliados positivamente e os indivíduos que os possuem teriam um status superior, enquanto os símbolos definidos como femininos são desprezados. O machismo explica por que a homossexualidade é mais punida em machos do que em fêmeas (ORTIZ-HERNÁNDEZ, 2005). O masculino é investido significativamente com a posição social (naturalizada) de agente do poder da violência, havendo, historicamente, uma relação direta entre as concepções vigentes de masculinidade e o exercício do domínio de pessoas, das guerras e das conquistas (MINAYO, 2005).

Vol. 02, N. 01, Jan. - Mar., 2019 - www.revistas.unilab.edu.br/index.php/rebeh 
As atitudes históricas e culturais negativas e condenatórias referentes a homossexuais moldaram uma sociedade hostil para tais pessoas. O resultado é que homossexuais estão expostos a tensões sociais durante todo o seu desenvolvimento, o que gera diversas consequências para a saúde física e mental de tais pessoas (PEREIRA, LEAL, 2002). Homossexuais acabam internalizando a homonegatividade social para si de diversas formas, levando-os à autodesvalorização, resultando em conflitos internos, pouca autoestima e não aceitação de seu desejo erótico e de sua identidade homossexual (PEREIRA, LEAL, 2005). A este movimento chamamos de homofobia internalizada.

Os dados sobre homofobia no Brasil revelam a necessidade de continuar se discutindo sobre a temática. Uma pesquisa sobre preconceito contra os homossexuais realizada pela UNESCO revelou que muitos estudantes não gostariam de ter um colega de classe homossexual e que as pessoas ainda consideram a homossexualidade doença. Além do que, pais de alunos não gostariam que os filhos tivessem colegas de sala homossexuais (FLEURY, TORRES, 2007; ABRAMOVAY, CASTRO, DA SILVA, 2004).

A não aceitação identitária através da HI poderia ser encarada como um fator preditivo para problemas de saúde mental, problemas de intimidade e comportamentos de risco em relação a IST's na medida em que induz à confusão identitária, à intolerância e à não-aceitação (PEREIRA, LEAL, 2005; ORTIZ HERNÁNDEZ, GARCÍA TORRES, 2005). A partir do exposto, questiona-se: O que a literatura entre 2010 - 2018 tem discorrido sobre a homofobia internalizada? Para responder tal questionamento, buscou-se identificar como a HI se manifesta e relacionar suas consequências para a pessoa.

\section{Caminhos metodológicos}

Este trabalho refere-se a uma pesquisa de natureza qualitativa, de cunho descritivo no formato de revisão de literatura. Para Minayo (2004) a abordagem qualitativa se preocupa com a produção de dados subjetivos através de rigoroso processo metodológico, permitindo a interpretação do pesquisado. Quanto ao estudo descritivo, este requer a sistematização do máximo de dados observados na realidade pesquisada.

Vol. 02, N. 01, Jan. - Mar., 2019 - www.revistas.unilab.edu.br/index.php/rebeh 
Tais pesquisas proporcionam novas visões sobre uma realidade já conhecida (GIL, 2008; PIOVESAN, TEMPORINI, 1995; CRESWELL, 2010; AUGUSTO et al, 2013, BREAKWELL et al, 2010).

Foram seguidas três etapas metodológicas neste estudo, sendo:

a) realização de um levantamento das publicações nas bases PEPSIC; SciELO; CAPES. Como critérios de inclusão, foram selecionados artigos científicos com configuração temporal entre 2010 a 2017, em português, inglês e espanhol, tendo como ponto norteador: Homofobia internalizada. Excluímos outras fontes de possíveis análises (livros, teses, dissertações e afins). Os descritores utilizados na coleta foram: "Homofobia AND internalizada". Dessa forma, os periódicos científicos que não obedeceram a esses critérios foram excluídos. A coleta foi realizada no período de fevereiro de 2018. A coleta inicial nos deu um total de 54 artigos, sendo 18 da base SCIELO, 10 da base PEPSIC e 26 da CAPES. Destes, excluímos 4 por se repetirem entre as bases.

b) Após essa etapa, foi realizada a leitura dos resumos dos 50 artigos restantes para exclusão dos que não abarcavam o tema proposto neste estudo (utilizamos como critério a adequação do artigo do ponto de vista dos objetivos e resultados ao tema proposto nesta análise - discutir HI). Nessa etapa metodológica, foram excluídos 28 artigos.

c) A terceira etapa foi a análise descritiva de cada artigo para elencar os resultados dos estudos e avaliar criticamente as contribuições oferecidas para a produção de conhecimento sobre a temática, que se deu a partir da criação de um instrumento pelos autores, para análise descritiva dos artigos, contendo título do artigo, identificação dos autores, tipos de pesquisa, ano de publicação, periódicos nos quais foram veiculados tais estudos, bases de dados de origem dos artigos, país de publicação, idiomas em que foram redigidos, objetivos e resultados obtidos.

De maneira geral, o panorama da seleção dos artigos está descrito a seguir:

Vol. 02, N. 01, Jan. - Mar., 2019 - www.revistas.unilab.edu.br/index.php/rebeh 


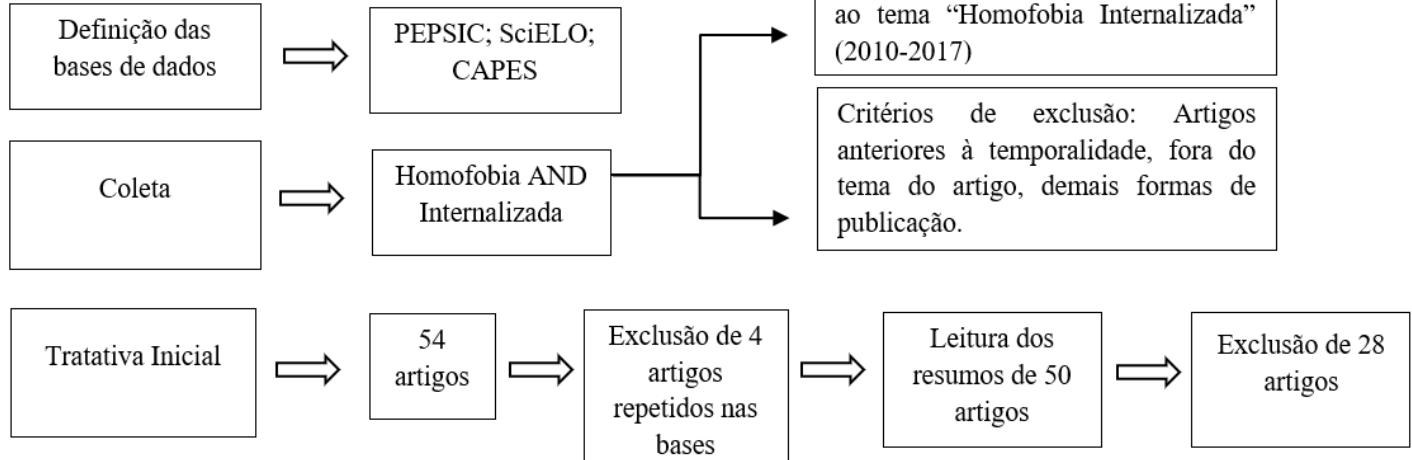

22 artigos

Figura 1 - Diagrama de seleção dos artigos

Fonte: Revisão da literatura

\section{Resultados e discussão}

Após a leitura dos títulos e resumos, foram selecionados 22 artigos científicos, escritos em língua portuguesa, inglesa e espanhola, cuja temática abordava a proposta deste estudo. A análise final dos artigos selecionados se deu conforme os critérios estabelecidos no protocolo. Na base PEPSIC foi encontrado um artigo relacionado ao tema, na base SciELO, foram encontrados quatro artigos e na CAPES foram encontrados 17 artigos.

Estes foram publicados no período entre 2010 e 2017, sendo que os anos que concentraram o maior número de publicações foram 2010 com 4 artigos, 2016 com 3 artigos e 2017 com 5 artigos. Os anos de 2014 e 2015 tiveram 02 publicações cada ano e os anos de 2012 e 2013 tiveram 03 publicações cada ano. Observa-se que as publicações são contínuas, com ausências de artigos publicados no ano de 2011.

Dessa forma, percebemos que em diferentes contextos e períodos de tempo diferenciados esta temática tem sido discutida pela comunidade acadêmica e isso é um dado muito importante. Considerando a abordagem metodológica, verifica-se que houve 
diversidade, abrangendo investigações qualitativas (50\%), teóricas (30\%), quantitativas $(17 \%)$ e mistas $(3 \%)$.

Observa-se que o país com maior número de publicações foi Brasil $(n=09)$, seguido pelo Colômbia $(n=6)$. Outro país com publicações foi a Espanha $(n=03)$, e Estados Unidos $(\mathrm{n}=02)$. Os outros dois artigos foram publicados no Canadá e no Chile. Os achados nos permitem identificar que existe uma concentração maior de discussões no contexto brasileiro, isso pode ser um dado relevante, visto que nosso país apresenta os maiores dados de violências contra essa população. Talvez esse seja um dos fatores que tenha levado a comunidade acadêmica a pesquisar e trazer para o centro das discussões temáticas como a homofobia internalizada.

Os 22 artigos selecionados estão distribuídos no quadro 1, a seguir:

Quadro 1 - Caracterização dos artigos analisados

\begin{tabular}{|c|c|c|c|c|c|}
\hline Base & Título do artigo & Autor(es) & Ano & País & Método \\
\hline \multirow[b]{4}{*}{$\frac{\varrho}{\varrho}$} & $\begin{array}{l}\text { Internalized homophobia as a partial mediator } \\
\text { between homophobic bullying and self-esteem } \\
\text { among youths of sexual minorities in Quebec } \\
\text { (Canada) }\end{array}$ & $\begin{array}{l}\text { BLAIS, GERVAIS, } \\
\text { HÉBERT. }\end{array}$ & 2014 & Canadá & Qualitativo \\
\hline & $\begin{array}{l}\text { Transtornos mentais, qualidade de vida e } \\
\text { identidade em homossexuais na maturidade e } \\
\text { velhice }\end{array}$ & $\begin{array}{l}\text { CEARÁ, } \\
\text { DALGALARRONDO. }\end{array}$ & 2010 & Brasil & Qualitativo \\
\hline & $\begin{array}{l}\text { Identidad sexual en jóvenes gay del norte de } \\
\text { Chile. }\end{array}$ & DELGADO et al. & 2016 & Chile & Qualitativo \\
\hline & $\begin{array}{l}\text { Corpos consumidos: cultura de consumo gay } \\
\text { carioca }\end{array}$ & PEREIRA, AYROSA & 2012 & Brasil & Qualitativo \\
\hline$\stackrel{\frac{e}{2}}{\frac{0}{0}}$ & $\begin{array}{l}\text { Homofobia Internalizada e Religiosidade entre } \\
\text { Casais Homoafetivos }\end{array}$ & $\begin{array}{l}\text { CERQUEIRA- } \\
\text { SANTOS et al. }\end{array}$ & 2017 & Brasil & Quali-Quanti \\
\hline \multirow[b]{4}{*}{$\sum_{\substack{0\\
}}^{\infty}$} & $\begin{array}{l}\text { Internalized homophobia in homosexual men: } \\
\text { a qualitative study }\end{array}$ & $\begin{array}{l}\text { CAMPO-ARIAS, } \\
\text { HERAZO, OVIEDO }\end{array}$ & 2015 & Colombia & Qualitativo \\
\hline & $\begin{array}{l}\text { Factores asociados con riesgo de suicidio de } \\
\text { adolescentes y jóvenes autoidentificados como } \\
\text { lesbianas, gays y bisexuales: estado actual de } \\
\text { la literatura }\end{array}$ & $\mathrm{ROA}$ & 2013 & Colômbia & Teórico \\
\hline & $\begin{array}{l}\text { Discrimination, Internalized Homonegativity, } \\
\text { and Attitudes Toward Children of Same-Sex } \\
\text { Parents: Can Secure Attachment Buffer } \\
\text { Against Stigma Internalization? }\end{array}$ & TRUB et al & 2017 & $\begin{array}{l}\text { Estados } \\
\text { Unidos }\end{array}$ & Quantitativo \\
\hline & 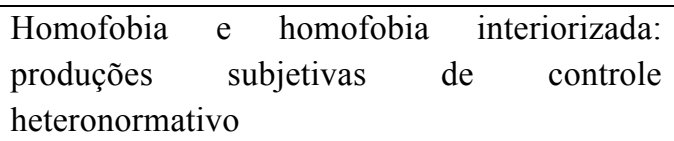 & NASCIMENTO & 2010. & Espanha & Teórico \\
\hline
\end{tabular}




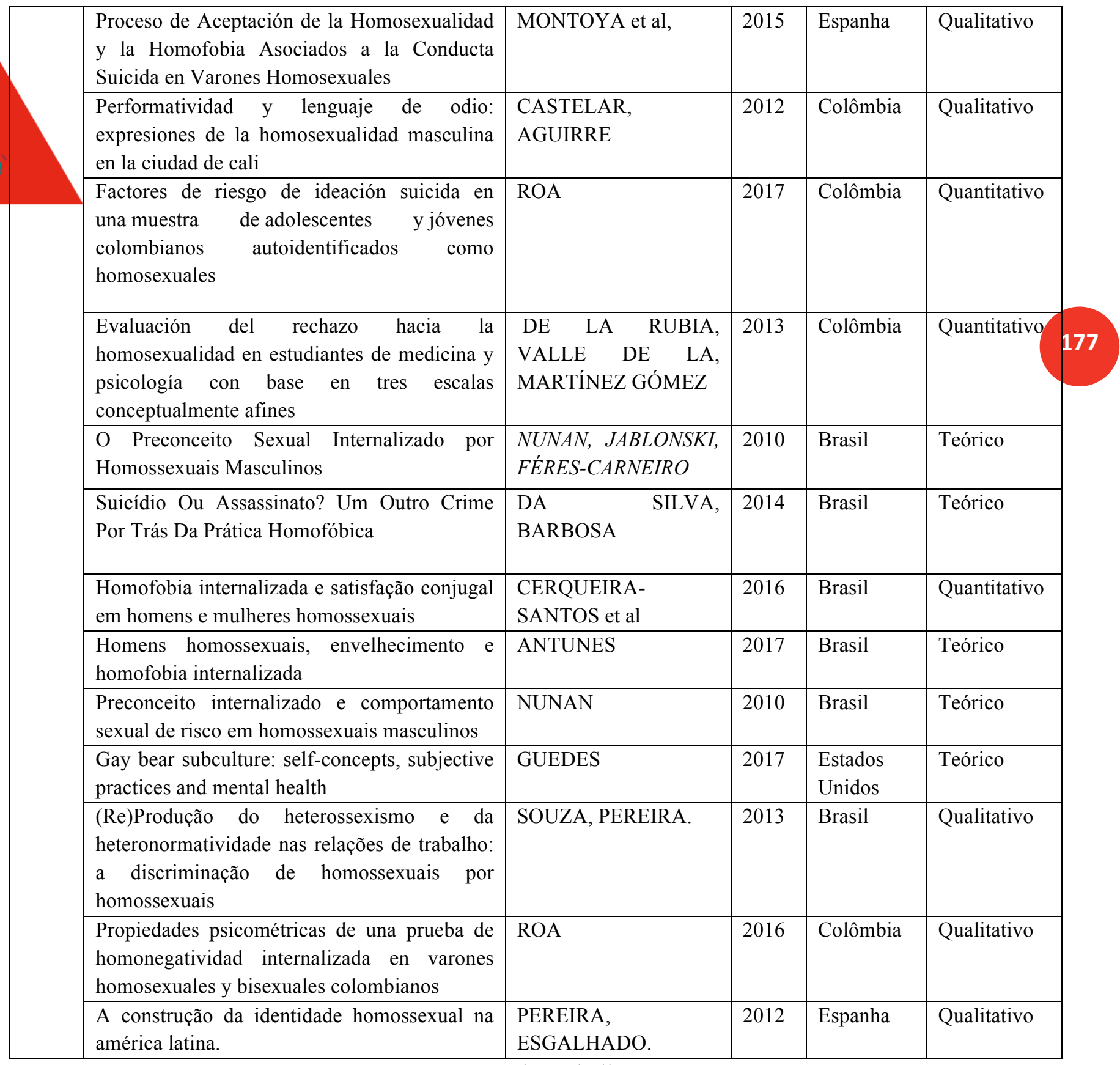

Fonte: Revisão da literatura

\section{Homofobia Internalizada: Manifestações e Consequências}


A análise da literatura mostrou que a HI se manifesta de diversas maneiras, porém todas elas trazem danos à saúde e bem-estar do sujeito (DE LA RUBIA, VALLE DE LA, GÓMEZ, 2013).

Roa (2013) enfatiza que não é novidade que a homossexualidade é severamente estigmatizada, devido ser a masculinidade uma questão histórica construída socialmente. O discurso que denigre os homossexuais está definido na história, começando pela Grécia antiga, assim como na Idade Média e grande parte da Idade Moderna, que via tal orientação como crime e pecado, passando pelo século XIX até três quartos do século $\mathrm{XX}$, onde ela passa a ser vista como doença mental. E na contemporaneidade vista como orientação sexual, sendo que nem em todas as culturas. A verdade é que os homossexuais se desenvolvem diante a um contexto de constante afirmação da masculinidade e onde a discriminação subtrai o valor individual humano.

Um dos achados mostrou que a transformação da homossexualidade em culpa tem base no sentimento social e ocorre quando o medo de perder o amor dos pais é generalizado como medo de perder o amor de todos. É o terror de perder esse amor que motiva a sublimação ou introversão dos desejos homoeróticos (CASTELAR, AGUIRRE, 2012).

Entre homossexuais, são grandes as chances de existir um nível de internalização da homofobia, devido à cultura heterossexista que propaga a idéia de que a homossexualidade é patológica e perversa (DE SOUZA, PEREIRA, 2013; NUNAN, JABLONSKI, FÉRES-CARNEIRO, 2010) e que os homossexuais são inferiores e que possuem defeito de caráter moral (NUNAN, 2010; ANTUNES, 2017).

A HI é a forma de se sentir, enquanto pessoa, inapropriada perante a sociedade em que vive. Esses sentimentos se relacionam ao sentimento de vergonha de si próprio, desenvolvido pela ordem crítica social heterossexista, que aumenta em toda a população LGBT a fragilidade, a insegurança e a instabilidade, causando angústia, mal-estar e momentos de baixa autoestima (NASCIMENTO, 2010). É preciso vencer a HI para construir uma identidade homossexual saudável (DELGADO et al, 2016; ROA, 2017).

A vergonha de sua orientação sexual faz com que os sujeitos percebam seus comportamentos sexuais de forma negativa, causando confusão identitária ao

Vol. 02, N. 01, Jan. - Mar., 2019 - www.revistas.unilab.edu.br/index.php/rebeh 
acreditarem que seus sentimentos e comportamentos não são normais (PEREIRA, ESGALHADO, 2012; DELGADO et al, 2016; CEARÁ, DALGALARRONDO, 2010).

Os estressores sociais associados à estima de ser homossexual leva a HI como aponta a teoria do stress minoritário (o termo "estresse minoritário" refere-se ao estresse que é experimentado por parte de uma minoria social) (ROA, 2017; BLAIS, GERVAIS, HÉBERT, 2014; NUNAN, 2010; GUEDES, 2018). Geralmente em sua infância e adolescência, essas pessoas ouviram por algum membro de sua família comentários hostis e pejorativos em relação à homossexualidade (MONTOYA et al, 2015). A população de homossexuais de maior idade teve mais contato com ideologias heterossexistas, desenvolvendo possivelmente mais sentimentos homofóbicos (CEARÁ, DALGALARRONDO, 2010).

A internalização da homofobia se dá quando alguns indivíduos de um grupo minoritário que sofre discriminação reagem identificando-se com as ideias do grupo maioritário, desenvolvendo assim um senso de autoestima defasada (BLAIS, GERVAIS, HÉBERT, 2014). Ela funciona um mecanismo psicológico de blindagem da própria identidade, mediante a qual se marca um limite que separa simbolicamente o indivíduo do grupo estigmatizado. Tais indivíduos, como forma de proteção, passam a aceitar o sistema de crenças que condena a orientação sexual não hegemônica. Trata-se de uma solução parcial para resolver o conflito entre a identidade e o sistema de crenças estabelecidos, onde as pessoas podem demonstrar uma verdadeira rejeição e desejo de mudança em relação à sua orientação homossexual (DELGADO et al, 2016; CERQUEIRA-SANTOS et al, 2017; TRUB, 2017).

Viver em uma sociedade que concebe heterossexualidade como a única opção para se relacionar em termos sexuais e amorosos influencia significativamente como homossexuais significam sua identidade sexual. Isso gera sofrimento em jovens gays em relação à sua própria identidade, podendo produzir diversos efeitos na saúde (DELGADO et al, 2016)

Nascimento (2010) e Antunes (2017) refletem sobre a dominação do masculino e a idéia cultural do heterocentrismo, que faz compreender a gênese da existência de apenas uma orientação sexual. Dessa forma, o heterocentrismo expõem toda a população

Vol. 02, N. 01, Jan. - Mar., 2019 - www.revistas.unilab.edu.br/index.php/rebeh 
LGBT como pessoas anormais, desprezíveis e esdrúxulas e reforça que esses seres são desviantes e ameaçadores da ordem heterossexual. E por pertencerem a um universo de sexo biológico definido de masculino e feminino na lógica do binarismo sexual, os LGBTs são compreendidos como excêntricos e desviantes.

Essa cultura manifesta nos homossexuais vergonha, sentimentos de ansiedade, raiva, aversão, repulsa e repúdio consigo mesmo e também culpa por serem atraídos por pessoas do mesmo sexo que eles. Os fazem reproduzir o heterossexismo hegemônico como exagerar nas características estereotipadas de seu gênero (como ser um homem muito musculoso na tentativa de "naturalizar-se", por exemplo) para proteger-se da discriminação e os fazem esconder seus desejos e todos os aspectos relacionados a sua sexualidade, inclusive na vida profissional, onde tende-se a escolher uma carreira que não esteja associada como ocupação "típica" não heterossexual, evitando-se manter contatos com pessoas ou movimentos homossexuais (NUNAN, JABLONSKI, FÉRESCARNEIRO, 2010; ROA, 2013; DELGADO et al, 2016; CAMPO-ARIAS, HERAZO, OVIEDO, 2015; PEREIRA, AYROSA, 2012; DE SOUZA, PEREIRA, 2013; GUEDES, 2018).

Sabe-se que antes de os homossexuais passarem pelo processo conhecido popularmente como "sair do armário", os sentimentos negativos sobre si mesmo e os constantes pensamentos de culpa, geralmente estão presentes para esses indivíduos. É uma forma de estresse interna e insidiosa" e constitui um obstáculo no caminho para a auto identificação completa com orientação sexual não heterossexual (ROA, 2017; DA SILVA, BARBOSA, 2014).

A identificação negativa e a HI geralmente faz com que homossexuais ocultem e neguem sua homossexualidade em algum momento de suas vidas. A HI também leva a esses homossexuais a descarregar em outros homossexuais os estereótipos e preconceitos negativos atribuídos à homossexualidade (MONTOYA et al, 2015).

A HI também gera uma forte rejeição em relação a outros gays que quebram o papel do gênero masculino esperado socialmente (jovens gays femininos). A rejeição do comportamento mais feminino em outros gays deriva da internalização de rígidos estereótipos de gênero que predominam na cultura heteronormativa (PEREIRA, 
AYROSA, 2012; ANTUNES, 2017). Apesar de manifestar uma orientação sexual diferente, homossexuais "devem" cumprir as expectativas do papel do gênero como parte de sua personalidade e identidade. Em homens homossexuais que reproduzem a estigmatização da HI, há um medo quase que constante de serem catalogados como femininos (DELGADO et al, 2016; DE SOUZA, PEREIRA, 2013).

A HI, de forma trágica e angustiante, interfere no papel das experiências existenciais do indivíduo homossexual, principalmente aqueles que acatam as regras sociais heteronormativas relacionadas ao binarismo de gênero (DA SILVA, BARBOSA, 2014; CAMPO-ARIAS, HERAZO, OVIEDO, 2015).

O "culto pela masculinidade" proposto pela heteronormatividade está amplamente ligado à HI. Porque se a masculinidade hegemônica não é expressa, alguns corpos podem ser lidos como se desejassem ser desprezados. Ser masculino é estar sujeito ao medo constante de perder tal condição (mesmo à custa de fazer com que o outro a perca), mas também o homem masculino é um "portador de dignidade". Qualquer tentativa de escapar das manifestações da masculinidade desperta suspeita. Existe preocupação em mostrá-la no cotidiano, na caminhada, gesticulação, roupas usadas etc. (CASTELAR, AGUIRRE, 2012; PEREIRA, AYROSA, 2012).

É comum encontrar em muitos imaginários sociais que a homofobia e o medo de reconhecer a própria homossexualidade estão intimamente relacionados (CASTELAR, AGUIRRE, 2012). A partir disso, encontrou-se que a HI pode manifesta-se na violência para com pessoas percebidas como homossexuais (cujas quais induzem estados de insegurança, medo extremo e vigilância de condutas como uma forma de negar sua condição) através de Bullying homofóbico (principalmente no cenário escolar), na aceitação do estigma sexual como parte do sistema de valores morais do indivíduo e na preocupação obsessiva com seu comportamento BLAIS, GERVAIS, HÉBERT, 2014; DE SOUZA, PEREIRA, 2013; ROA, 2016; CERQUEIRA-SANTOS et al, 2016; NUNAN, JABLONSKI, FÉRES-CARNEIRO, 2010; DA SILVA, BARBOSA, 2014; MONTOYA et al, 2015).

Um dos aspectos relacionados a HI é a vivência de uma "falsa heterossexualidade" em espaços públicos e a vivência do desejo proibido em espaços

Vol. 02, N. 01, Jan. - Mar., 2019 - www.revistas.unilab.edu.br/index.php/rebeh 
privados ou até mesmo no anonimato através de um código de conduta fundamentado na “discrição” (DE SOUZA, PEREIRA, 2013; ANTUNES, 2017; DELGADO et al, 2016).

Outro aspecto foi observado na pesquisa de Campo-Arias, Herazo, Oviedo (2015), onde homens homossexuais que solicitavam amizade ou relações sexuais com outros homens via internet expressavam abertamente sua HI de formas implícitas e explícitas, o que sugeria a aceitação do modelo hegemônico de um "homem masculino" através de frases como: "Não sou e não curto afeminado". Afirmações sobre gênero acabam por funcionar como um reforçador da HI: "Tudo bem ser gay mas não pode ser viadinho". Quanto mais o indivíduo é "afeminado", mais estigmatizado ele será (PEREIRA, AYROSA, 2012).

Os dispositivos sociais, como tradições e religiosidade trazem a prescrição dos regulamentos de controle institucionais, que conferem à heterossexualidade orientação do desejo afetivo-sexual como correta, única e válida (ANTUNES, 2017; NUNAN, 2010). Assim, a relação entre religiosidade e HI é evidenciada, pois, em resumo, a religião condena o comportamento homossexual com uma espécie de discurso disciplinatório: Heterossexualidade é o natural e a Homossexualidade é anormal, influenciando diretamente no juízo de valor dos indivíduos (DE SOUZA, PEREIRA, 2013; CERQUEIRA-SANTOS et al, 2016; DA SILVA, BARBOSA, 2014; PEREIRA, ESGALHADO, 2012).

O jovem homossexual religioso, através do processo de blindagem da própria identidade, reproduz tal discurso, o que acabará afetando seu bem-estar, difundindo ideais preconceituosos que serão direcionados, inclusive, a ele mesmo. Altos níveis de religiosidade geralmente estão presentes em sujeitos que apresentaram altos níveis de HI (CERQUEIRA-SANTOS et al, 2017). Um menor grau de HI está associado a uma maior aceitação da orientação sexual. Em particular, os homens que se definem como bissexuais tendem a marcar mais alto no homofobia internalizada (ROA, 2017).

Predominantemente, há, através da internalização da homofobia, uma grande insatisfação consigo mesmo (CERQUEIRA-SANTOS et al, 2017; DELGADO et al, 2016; TRUB et al, 2017). A qualidade de vida dos homossexuais que necessitavam administrar uma vida gay/lésbica oculta e distinta de uma aparente vida como

Vol. 02, N. 01, Jan. - Mar., 2019 - www.revistas.unilab.edu.br/index.php/rebeh 
heterossexual, mostrou-se significativamente pior no domínio geral e físico em comparação aos sujeitos que se revelavam totalmente como homossexuais (CEARÁ, DALGALARRONDO, 2010).

É bem conhecido que os não heterossexuais relatam pior saúde mental do que os heterossexuais. A HI é parte do estresse derivado do status de minoria sexual relacionado à estigmatização crônica, preconceito e discriminação. Pessoas não heterossexuais que relatam alta $\mathrm{HI}$ estão em risco aumentado de sofrimento emocional e transtornos mentais (CAMPO-ARIAS, HERAZO, OVIEDO, 2015). A relação entre ter experienciado sentimentos de vergonha diante da sua orientação sexual e apresentar algum transtorno mental é estatisticamente significativa (CEARÁ, DALGALARRONDO, 2010). A internalização do estigma homofóbico leva os jovens LGBT a temer a rejeição futura, prejudicando seu senso de valor relacional (BLAIS, GERVAIS, HÉBERT, 2014).

Encontramos na literatura que a HI está relacionada a comportamentos automutilatórios e pode se estender ao abuso de substâncias, transtornos alimentares, comportamento sexual de risco e o suicídio propriamente consumado (essa afirmação descreve que jovens gays e lésbicas tem maior probabilidade de risco e tentativa suicida), além de baixa autoestima, isolamento social e emocional, conflitos parentais e conjugais, oscilações de humor e afeto (raiva, medo, culpa, vergonha, sentir-se rejeitado, desprezo), reações físicas (crises de choro, cansaço e exaustão física), projeção de preconceitos (DELGADO et al, 2016; MONTOYA et al, 2015; (NUNAN, JABLONSKI, FÉRES-CARNEIRO, 2010; DA SILVA, BARBOSA, 2014; ANTUNES, 2017; NUNAN, 2010; GUEDES, 2018; DE SOUZA, PEREIRA, 2013; ROA, 2016; PEREIRA, AYROSA, 2012; PEREIRA, ESGALHADO, 2012). As orientações sexuais e o suicídio estabelecem um efeito indireto condicionado pelo grau de rejeição social (ROA, 2013).

De acordo com Nascimento (2010) a HI produz medo e proporciona sofrimento subjetivo existencial das vivências do sujeito homossexual. A forma desprezível e hostil de como são tratados na sociedade é aceita muitas vezes, pela culpa que sentem por não seguirem padrões heterossexuais.

Vol. 02, N. 01, Jan. - Mar., 2019 - www.revistas.unilab.edu.br/index.php/rebeh 
A HI repercute negativamente na vida e no amadurecimento sexual e culmina em dificuldades nos relacionamentos afetivo/amorosos (CERQUEIRA-SANTOS et al, 2016). Foi encontrado também a extrema passividade e vulnerabilidade emocional (aspecto da personalidade em que a pessoa se coloca à disposição, em prol de tudo a fim de ser aceito e/ou amado, respeitado) relacionado a HI (ANTUNES, 2017; NUNAN, 2010).

\section{Considerações finais}

A análise da literatura nos permitiu encontrar subsídios para afirmar que a $\mathrm{HI}$ prejudica o sujeito em todos os âmbitos de sua vida. Partindo do princípio de que somos sujeitos sócio interacionistas, a qualidade da saúde mental afeta diretamente a qualidade da saúde física e o contrário também. A teoria do estresse minoritário nos ajuda a entender por que homossexuais estão em maior vulnerabilidade para o uso de substâncias psicoativas e suicídio, bem como nos dá subsídios para discutir o porquê de a saúde mental desses sujeitos ser predominantemente pior em relação a heterossexuais.

A literatura aponta uma relação direta entre HI e saúde mental, onde a superação dos significados homofóbicos internalizados no decorrer da construção de sua subjetividade é essencial para a formação de uma identidade saudável, vivência da sexualidade de maneira plena e recuperação da saúde mental roubada durante o processo de desenvolvimento.

Ser homossexual requer uma postura constante de resistência. Esses sujeitos são fuzilados de diversos lados por violências que os atingem globalmente. A heteronormatividade age a partir de um discurso de controle cruel sobre os corpos e faz com que homossexuais sofram por não se adequarem aos seus preceitos e até mesmo faz com que esses sujeitos sofram na tentativa de se adequarem.

Além de a HI ser prejudicial para o homossexual em si, ela também prejudica e ataca outros homossexuais que não atendem as normas de gênero (principalmente aqueles que afrontam a hipermasculinidade). A projeção de suas inseguranças e medos 
na forma de ódio reforça a exclusão de outros homossexuais, culminando assim em mais HI.

Por fim, a literatura nos mostrou que para o enfrentamento da homofobia, é preciso o comprometimento de diversos atores sociais para a desconstrução da heteronormatividade como única forma possível de vivência de gênero e sexualidade para que outros sujeitos possam viver de maneira plena seus desejos.

\section{Referências}

ABRAMOVAY, M.; CASTRO, M. G.; DA SILVA, L. B. Juventude e sexualidade. Brasília: UNESCO Brasil, 2004.

ANTUNES, P. S. Homens homossexuais, envelhecimento e homofobia internalizada. Revista Kairós - Gerontologia, São Paulo, v. 20, n. 1, p. 311-335, 2017. Disponível em https://revistas.pucsp.br/index.php/kairos/article/download/33502/23086. Acessos em 19 de Agosto de 2018.

AUGUSTO, C. A. et al. Pesquisa Qualitativa: rigor metodológico no tratamento da teoria dos custos de transação em artigos apresentados nos congressos da Sober (20072011). Rev. Econ. Sociol. Rural, Brasília, v.v51, n. 4, p. 745-764, 2013. Disponível em http://www.scielo.br/scielo.php?script=sci_arttext\&pid=S0103-

20032013000400007\&lng=en\&nrm=iso. Acessos em 19 de Agosto de 2018.

BLAIS, M.; GERVAIS, J.; HEBERT, M. Internalized homophobia as a partial mediator between homophobic bullying and self-esteem among youths of sexual minorities in Quebec (Canada). Ciênc. saúde coletiva, Rio de Janeiro, v. 19, n. 3, p. 727-735, Mar. 2014.

Disponível

em

http://www.scielo.br/scielo.php?script=sci_arttext\&pid=S1413-

81232014000300727\&lng=en\&nrm=iso. Acessos em 19 de Agosto de 2018.

BREAKWELL, G. M et al. Métodos de pesquisa em psicologia. Porto Alegre; Artmed; 3 ed; 2010.

CAMPO-ARIAS, A., HERAZO, E.; OVIEDO, L. Internalized homophobia in homosexual men: a qualitative study. Revista Duazary - Revista de la Facultad de Ciencias de la Salud, Bogotá, v. 12, n. 2, 2015. Disponívem em: https://dialnet.unirioja.es/descarga/articulo/5156564.pdf. Acesso em 19 de Agosto de 2018.

CASTELAR, A. F.; AGUIRRE, F. Q. Performatividad y lenguaje de odio: expresiones de la homosexualidad masculina en la ciudad de cali. Revista CS, Cali, n. 10, p. 207239 , 2012.

Disponpivel

em http://www.scielo.org.co/scielo.php?script=sci_arttext\&pid=S201103242012000200007\&lng=en\&nrm=iso. Acessos em 19 de Agosto de 2018.

CEARA, A. T.; DALGALARRONDO, P. Transtornos mentais, qualidade de vida e identidade em homossexuais na maturidade e velhice. Rev. psiquiatr. clín. São Paulo,

Vol. 02, N. 01, Jan. - Mar., 2019 - www.revistas.unilab.edu.br/index.php/rebeh 
v. 37, $\quad$ n. 3, p. 118-123, 2010. Disponível em http://www.scielo.br/scielo.php?script=sci_arttext\&pid=S0101$60832010000300005 \& \operatorname{lng}=$ en\&nrm=iso. Acesso em 19 de agosto de 2018.

CERQUEIRA-SANTOS, E. et al. Homofobia internalizada e religiosidade entre casais homoafetivos. Temas psicol., Ribeirão Preto, v. 25, n. 2, p. 691-702, jun. 2017

Disponível em http://pepsic.bvsalud.org/scielo.php?script=sci_arttext\&pid=S1413389X2017000200015\&lng=pt\&nrm=iso. Acessos em 19 de Agosto de 2018.

, et al. Homofobia internalizada e satisfação conjugal em homens e mulheres homossexuais. Contextos Clínic, São Leopoldo, v. 9, n. 2, p. 148-158, 2016. Disponível em http://pepsic.bvsalud.org/scielo.php?script=sci_arttext\&pid=S198334822016000200002\&lng=pt\&nrm=iso. Acessos em 19 Ago. 2018.

COSTA, Â. B.; NARDI, H. C. Homofobia e preconceito contra diversidade sexual: debate conceitual. Temas psicol., Ribeirão Preto, v. 23, n. 3, p. 715-726, 2015. Disponível em http://pepsic.bvsalud.org/scielo.php?script=sci_arttext\&pid=S1413389X2015000300015\&lng=pt\&nrm=iso. Acessos em 19 ago. 2018.

CRESWELL, J. W. Projeto de pesquisa. Métodos qualitativo, quantitativo e misto. Porto Alegre: Artmed, 2010.

DE LA RUBIA, J, M.; VALLE DE LA, A.; MARTÍNEZ GÓMEZ, E. Evaluación del rechazo hacia la homosexualidad en estudiantes de medicina y psicología con base en tres escalas conceptualmente afines. Psicología desde el Caribe, v. 30, n. 3, p. 526-550, 2013. Disponível em: http://www.redalyc.org/articulo.oa?id=21329176005. Acessos em 19 de Agosto de 2018.

DE SOUZA, E. M.; PEREIRA, S. J. N. (Re)produção do heterossexismo e da heteronormatividade nas relações de trabalho: a discriminação de homossexuais por homossexuais. RAM, Rev. Adm. Mackenzie, São Paulo, v. 14, n. 4, p. 76-105, 2013. Disponível em http://www.scielo.br/scielo.php?script=sci_arttext\&pid=S167869712013000400004\&lng=en\&nrm=iso. Acessos em 19 de Agosto de 2018.

DELGADO, J. E. B. et al. Identidad sexual en jóvenes gay del norte de Chile. Sex., Salud Soc., Rio de Janeiro, n. 23, p. 118-139, 2016. Disponível em http://www.scielo.br/scielo.php?script=sci_arttext\&pid=S1984-

64872016000200118\&lng=en\&nrm=iso. Acessos em 19 de Agosto de 2018.

FLEURY, A. R. D.; TORRES, A. R. R. Análise psicossocial do preconceito contra homossexuais. Estud. psicol. (Campinas), Campinas, v. 24, n. 4, p. 475-486, 2007. Disponível em: http://www.scielo.br/scielo.php?script=sci_arttext\&pid=S0103166X2007000400007\&lng=en\&nrm=iso. Acessos em 19 de Ago. de 2018.

GIL, A. C. Como elaborar projetos de pesquisa. 5. ed. São Paulo: Atlas, 2008.

GUEDES, D. D. Subcultura gay bear: autoconceitos, práticas subjetivas e saúde mental. Revista Psicologia, Diversidade e Saúde, Salvador, v. 7, n.1, p. 120-132, 2018. Disponível em: https://www5.bahiana.edu.br/index.php/psicologia/article/view/1574/1679. Acessos em 19 de Agosto de 2018.

Vol. 02, N. 01, Jan. - Mar., 2019 - www.revistas.unilab.edu.br/index.php/rebeh 
DA SILVA, L, V.; BARBOSA B. R. S. N. Suicídio Ou Assassinato? Um Outro Crime Por Trás Da Prática Homofóbica. Periódico do NEP sobre Gênero e Direito Belém, n, 2, p. 58-78, 2014. $\quad$ Disponível em http://www.periodicos.ufpb.br/ojs/index.php/ged/article/view/20346. Acessos em 19 de Agosto de 2018.

MELLO, R. P. Corpos, heteronormatividade e performances híbridas. Psicol Soc. Belo Horizonte, v. 24, n. 1, p. 197-207, 2012. Disponível em http://www.scielo.br/scielo.php?script=sci_arttext\&pid=S0102$71822012000100022 \& \operatorname{lng}=$ en\&nrm=iso. Acesso em 19 de agosto de 2018.

MINAYO, M. C. S. Laços separam o machismo e a violência. Ciênc. saúde coletiva, Rio de Janeiro, v. 10, n. 1, p. 23-26, março de 2005. Disponível em http://www.scielo.br/scielo.php?script=sci_arttext\&pid=S1413-

81232005000100005\&lng=en\&nrm=iso. Acesso em 19 de agosto de 2018.

Hucitec, 2004.

MONTOYA, R. Q. et al. Proceso de Aceptación de la Homosexualidad y la Homofobia Asociados a la Conducta Suicida en Varones Homosexuales. Masculinities and Social Change, La Roja, v.4, n,1, p. 1-25, 2015. Disponível em https://dialnet.unirioja.es/servlet/articulo?codigo=4991358b. Acessos em 19 de Agosto de 2018.

NASCIMENTO, M. A. N. Homofobia e homofobia interiorizada: produções subjetivas de controle heteronormativo. Athenea Digital, Barcelona, n.17, p.227-239, 2010. Disponível em: http://atheneadigital.net/article/view/n17-nascimento. Acessos em 19 de Agosto de 2018.

NUNAN, A. Preconceito internalizado e comportamento sexual de risco em homossexuais masculinos. Psicol. Argum., Curitiba, v. 28, n. 62, p. 247-259, 2010. Disponível

em https://periodicos.pucpr.br/index.php/psicologiaargumento/article/view/19941/19237.

Acessos em 19 de Agosto de 2018.

NUNAN, A., JABLONSKI, B.; FÉRES-CARNEIRO, T. O Preconceito Sexual Internalizado por Homossexuais Masculinos. Interação Psicol., v.14, n. 2, p. 255-262, 2010. Disponível em https://revistas.ufpr.br/psicologia/article/view/12212. Acessos em 19 de Agosto de 2018.

ORTIZ-HERNANDEZ, L. Influencia de la opresión internalizada sobre la salud mental de bisexuales, lesbianas y homosexuales de la Ciudad de México. Salud Ment, México, v. 28, n. 4, p. 49-65, 2005. 4 Disponivel em http://www.scielo.org.mx/scielo.php?script=sci_arttext\&pid=S018533252005000400049\&lng=es\&nrm=iso. Acessos em 19 de agosto 2018.

; GARCIA TORRES, M. I. Opresión internalizada y prácticas sexuales de riesgo en varones homo-y bi-sexuales de México. Rev. Saúde Pública, São Paulo, v. 39, n. $6, \mathrm{p}$. 956-964, 2005.

Disponível em 
http://www.scielo.br/scielo.php?script=sci_arttext\&pid=S0034-

89102005000600014\&lng=en\&nrm=iso. Accessos em 19 de Agosto de 2018.

PEREIRA, C. R. et al. Preconceito contra homossexuais e representações sociais da homossexualidade em seminaristas católicos e evangélicos. Psic.: Teor. e Pesq., Brasília, v. 27, n. 1, p. 73-82, 2011. Disponível em: http://www.scielo.br/scielo.php?script=sci_arttext\&pid=S0102-

37722011000100010\&lng=en\&nrm=iso. Acessos em 19 de agosto de 2018.

PEREIRA, H.; ESGALHADO, G. A construção da identidade homossexual na américa latina. INFAD Revista de Psicología, v.4, n.1, p. 169-178, 2012. Disponível em http://dehesa.unex.es/bitstream/handle/10662/3041/0214-

9877_2012_1_4_169.pdf?sequence=1. Acessos em 19 de Agosto de 2018.

PEREIRA, H.; LEAL, I. P. A homofobia internalizada e os comportamentos para a saúde numa amostra de homens homossexuais. Aná. Psicológica, Lisboa, v. 20, n. 1, p. 107-113, 2002.

Disponível

em

http://www.scielo.mec.pt/scielo.php?script=sci_arttext\&pid=S0870-

82312002000100010\&lng=pt\&nrm=iso. Acessos em 19 Ago. 2018.

. A identidade (homo)sexual e os seus determinantes: Implicações para a saúde. Aná. Psicológica, Lisboa, v. 23, n. 3, p. 315-322, jul. 2005 . Disponível em http://www.scielo.mec.pt/scielo.php?script=sci_arttext\&pid=S0870-

82312005000300010\&lng=pt\&nrm=iso. Acessos em 19 Ago. 2018.

PEREIRA, H.; LEAL, I. P. Medindo a homofobia internalizada: A validação de um instrumento. Aná. Psicológica, Lisboa, v. 23, n. 3, p. 323-328, jul. 2005 . Disponível em http://www.scielo.mec.pt/scielo.php?script=sci_arttext\&pid=S087082312005000300011\&lng=pt\&nrm=iso. Acessos em 19 Ago. 2018.

PEREIRA, S. J. N.; AYROSA, E. A. T. Corpos consumidos: cultura de consumo gay carioca. Órgão. Soc. Salvador, v. 19, n. 61, p. 295-313, 2012. Disponível em http://www.scielo.br/scielo.php?script=sci_arttext\&pid=S1984-

92302012000200007\&lng=en\&nrm=iso. Acesso em 19 de agosto de 2018.

PIOVESAN, A.; TEMPORINI, E. R. Pesquisa exploratória: procedimento metodológico para o estudo de fatores humanos no campo da saúde pública. Rev. Saúde Pública, São Paulo, v. 29, n. 4, p. 318-325, 1995. Disponível em http://www.scielo.br/scielo.php?script=sci_arttext\&pid=S0034-

89101995000400010\&lng=en\&nrm=iso. Acessos em 19 de Agosto de 2018.

RIOS, R. R. O conceito de homofobia na perspectiva dos direitos humanos e no contexto dos estudos sobre preconceito e discriminação In: POCAHY, F. (organizador). Rompendo o silêncio: homofobia e heterossexismo na sociedade contemporânea. Porto Alegre: Nuances, 2007. p. 27-48.

ROA, C. A. P. Factores asociados con riesgo de suicidio de adolescentes y jóvenes autoidentificados como lesbianas, gays y bisexuales: estado actual de la literatura. Rev Colomb Psiquiatr. Bogotá, v. 42, p.333-49, 2013. Disponível em http://www.elsevier.es/es-revista-revista-colombiana-psiquiatria-379-articulo-factoresasociados-con-riesgo-suicidio-S0034745013700301. Acessos em 29 de Agosto de 2018.

Vol. 02, N. 01, Jan. - Mar., 2019 - www.revistas.unilab.edu.br/index.php/rebeh 
. Factores de riesgo de ideación suicida en una muestra de adolescentes y jóvenes colombianos autoidentificados como homosexuales. Rev Colomb Psiquiat. Bogotá p.18, 2017. Disponível em http:/www.elsevier.es/es-revista-revista-colombiana-psiquiatria379-avance-factores-riesgo-ideacion-suicida-unamuestra-S0034745017300720. Acessos em 19 de Agosto de 2018.

. Propiedades psicométricas de una prueba de homonegatividad internalizada en varones homosexuales y bisexuales colombianos. Psicología desde el Caribe, v. 33, n 1, p. 47-65, 2016. Disponível em $<$ http://rcientificas.uninorte.edu.co/index.php/psicologia/article/view/6545/8377. Acessos em 19 de Agosto de 2018.

TRIVIÑOS, A. N. S. Introdução à pesquisa em ciências sociais: a pesquisa qualitativa em educação. São Paulo: Atlas, 2008.

TRUB, L et al. Discrimination, Internalized Homonegativity, and Attitudes Toward Children of Same-Sex Parents: Can Secure Attachment Buffer Against Stigma Internalization? Fam Process. v.56, n.3, p. 701-715, 2017. Disponível em: https://onlinelibrary.wiley.com/doi/abs/10.1111/famp.12255. Acesso: em 19 de Agosto de 2018.

\title{
INTERNALIZED HOMOPHOBIA:
}

\author{
REVIEW OF SCIENTIFIC LITERATURE
}

\begin{abstract}
This study is characterized by a literature review that deals with the production of Internalized Homophobia (HI) between 2010-2017. We aim to discuss how the literature approaches its manifestation, which factors related to it and its consequences. For this, we selected 22 articles through the descriptors "Homophobia AND Internalized" of the databases Scielo, Pepsic and CAPES in the Portuguese, English and Spanish languages. The collected articles were analyzed through a protocol created by the authors. The results discuss that homosexuals internalize the stigma against homosexuality from a very young age and this harms them in the formation of a healthy identity, besides that they are in greater vulnerability to the use of alcohol and other drugs and suicide. HI is designed in the form of hatred against homosexuals who do not respond to gender binarism and reaches even more strongly the so-called "effeminate" homosexuals. Religion has a strong role in the internalization of stigmata, and it is necessary to overcome HI to live their sexual orientation in a healthy and full way.
\end{abstract}

Keywords: Internalized Homophobia; Heteronormativity; Consequences; Literature review.

Recebido em: 15/01/2019

Aceito em: 15/02/2019

Vol. 02, N. 01, Jan. - Mar., $2019 \cdot$ www.revistas.unilab.edu.br/index.php/rebeh 